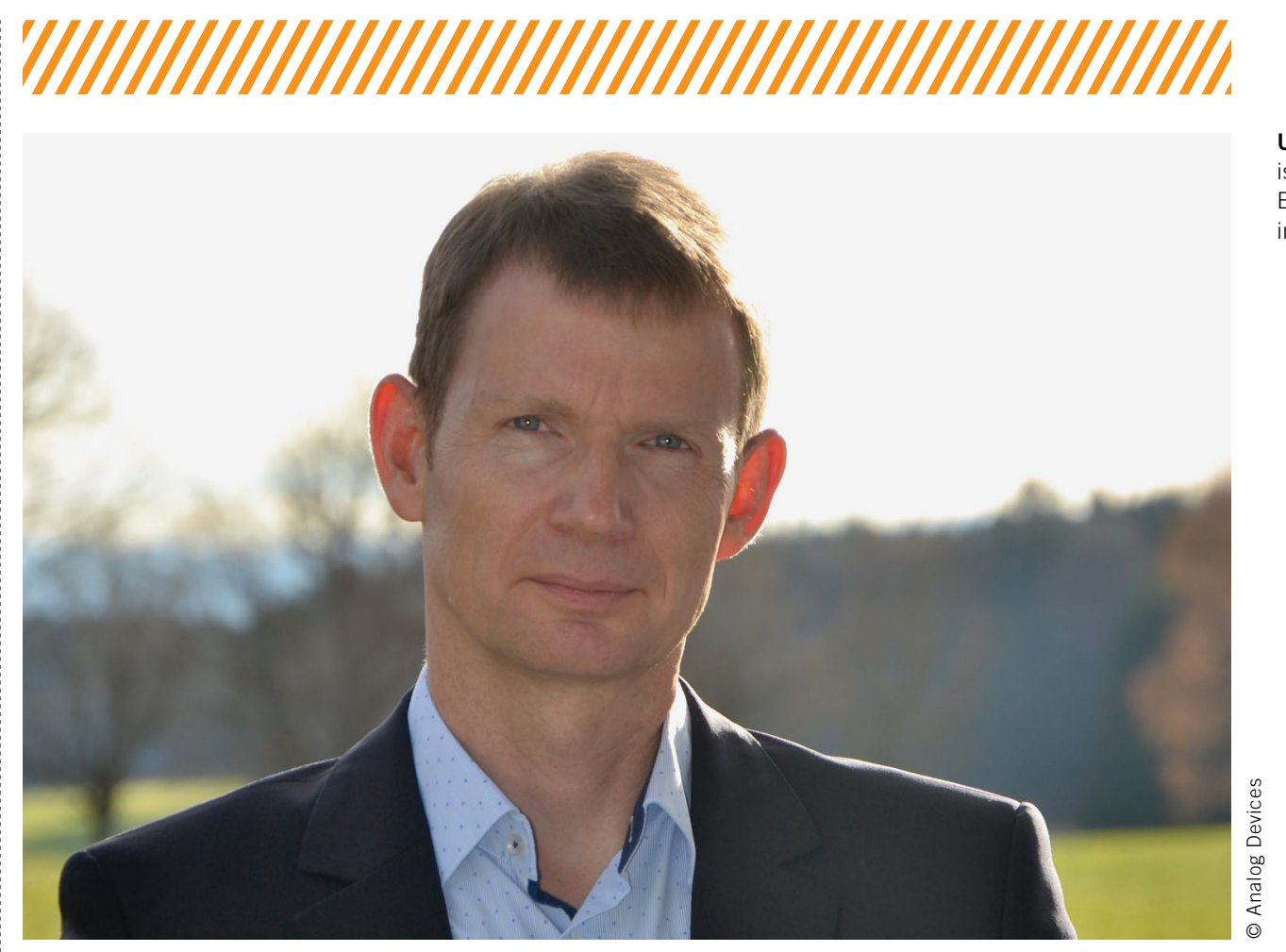

Uwe Bröckelmann

ist Senior Director of Technology, E-Mobility bei Analog Devices in München

\title{
Standardisierung hilft auch bei Traktionsbatterien
}

Der Verkauf von batterieelektrischen Fahrzeugen (BEVs) zieht aktuell deutlich an. Liegt das an der weltweiten Pandemie, wie mancherorts zu lesen ist? Sicher nicht! Wohl eher daran, dass jetzt von etablierten Herstellern interessante Modelle zum Verkauf stehen und diese dank Förderung auch in einem akzeptablen Preisrahmen liegen. Die deutsche oder europäische Autoindustrie hat das Thema Elektrifizierung also nicht verschlafen, sondern geht jetzt in den Markt, wo aufgrund deutlicher Kostensenkungen und Effizienzsteigerungen bei der Batterietechnologie eine positive Rendite mit Elektrofahrzeugen erreichbar ist.

Allerdings ist der Kostendruck immer noch sehr hoch und das Ziel weit entfernt, die Kosten eines BEVs in den Bereich eines vergleichbaren Verbrennerfahrzeugs zu bekommen. Im Kleinwagenbereich wird man das wahrscheinlich auf absehbare Zeit nicht erreichen, aber es gibt grundsätzlich noch einiges an Kostensenkungspotenzial, das sich über einen Systemansatz erreichen lässt. So wird heute versucht, den durch Wegfall des Verbrenners vorhandenen Bauraum möglichst raumoptimiert auszunutzen. Das führt dazu, dass bei jeder Fahrzeugplattform unterschiedliche Batterie-Modulgrößen in die Traktionsbatterie integriert sind und bei einigen Fahrzeugen sogar die Zellanzahl pro Modul innerhalb einer Batterie nicht konstant ist. Dieser Variantenreichtum sorgt nicht nur beim Fahrzeughersteller für Mehraufwand, auch die Halbleiterhersteller müssen dazu unter- schiedlichste Kanalzahlen in ihren Batterie-Überwachungsbausteinen anbieten. Dadurch steigen die Entwicklungskosten, und die Volumina pro Bausteinvariante sinken.

Standardisierung in Bereichen, die nicht wettbewerbsdifferenzierend sind, hat die Autoindustrie schon immer stark gemacht. Das sollte jetzt auch im Bereich von Traktionsbatterien umgesetzt werden. So würde beispielsweise eine Standardisierung der Kanalzahlen für Zellüberwachungsbausteine auf 16 Kanäle der gesamten Industrie helfen und damit die Variantenvielfalt begrenzen. Dies wäre für die beiden meist verwendeten ZellChemien NMC (Nickel-Mangan-Cobalt) beziehungsweise LFP (Lithium-Eisen-Phosphat) ein geeigneter Wert, da damit die Maximalspannung je Modul bei Erreichen der Ladeschlussspannung unter der Berührungsschutzgrenze von $60 \mathrm{~V}$ gehalten werden kann. Ohne Änderungen der Zellüberwachungs-Hardware könnten dann in ein Modul bis zu 16 LFP- und bis zu 14 NMC-Zellen in Serie untergebracht werden und einzelne Module ohne Zusatzmaßnahmen zum Hochspannungsschutz transportiert, gelagert und verarbeitet werden. Die gleiche Standardisierung wäre auch anwendbar auf $48 \mathrm{~V}$-Batterien, die auch meistens mit LFP- oder auch NMC-Zellen aufgebaut sind. Sicherlich gibt es noch weitere Bereiche, die in einem E-Fahrzeug vereinheitlicht werden können, ohne dass sich daraus die Möglichkeiten der Marken- und Fahrzeugdifferenzierung einschränken würden. 